Check for updates

Cite this: RSC Adv., 2019, 9, 15531

Received 25th December 2018

Accepted 13th May 2019

DOI: $10.1039 / \mathrm{c} 8 \mathrm{ra10564b}$

rsc.li/rsc-advances

\title{
Efficient one-pot green synthesis of tetrakis(acetonitrile)copper(I) complex in aqueous media†
}

\author{
Ilya S. Kritchenkov, (D) Julia R. Shakirova (D) and Sergey P. Tunik (D) *
}

New simple, fast, effective and environmentally friendly one-pot method for the synthesis of extensively used tetrakis(acetonitrile)copper(I) complexes with $\mathrm{BF}_{4}{ }^{-}, \mathrm{PF}_{6}{ }^{-}$and $\mathrm{ClO}_{4}{ }^{-}$counterions is invented and optimized. The approach suggested allows using water as solvent and minimizes amounts of toxic organic reagents in the synthetic protocol.

\section{Introduction}

Labile tetrakis-acetonitrile complexes of the $\left[\mathrm{Cu}\left(\mathrm{CH}_{3} \mathrm{CN}\right)_{4}\right] \mathrm{X}$ type, where $\mathrm{X}=\mathrm{BF}_{4}{ }^{-}, \mathrm{PF}_{6}{ }^{-}, \mathrm{ClO}_{4}{ }^{-}$(ref. 1 and 2) are widely used in research laboratories and industrial processes as catalysts in cycloaddition ${ }^{3,4}$ and Ullmann ${ }^{5}$ reactions, intramolecular aromatic annulations, ${ }^{6,7}$ oxidation of primary alcohols $^{8}$ and many other popular reactions of organic synthesis. ${ }^{9-13}$ At the same time they serve as important precursors for the synthesis of overwhelming majority of mononuclear ${ }^{14-16}$ and homo- ${ }^{17}$ and hetero-polynuclear ${ }^{18,19}$ copper(I) complexes, which also have numerous practical applications, ${ }^{20-22}$ one of which is large-scale production of emitting materials for OLED fabrication. ${ }^{23}$ Total number of references related to these compounds as reagents/reactants exceeds 3100 (over 100 of them during 2018 year), including the papers in journals of highest rank. It is obvious that production of these compounds is of great importance for research and industry and simple, economical and environmentally friendly method of synthesis is of high demand.

Complexes of the $\left[\mathrm{Cu}\left(\mathrm{CH}_{3} \mathrm{CN}\right)_{4}\right] \mathrm{X}$ type with bulky counterions are known for many decades since the 1923 when the first representative of this family was isolated by the reduction of silver nitrate with copper powder in acetonitrile. ${ }^{24}$ Since then the synthetic procedures were modified to exclude expensive $\operatorname{Ag}(\mathrm{I})$ salts from the reaction scheme. At present time there are two major ways for the synthesis of this complexes: the first one consists in direct interaction of copper(I) oxide with the corresponding acid in acetonitrile (Scheme 1A), ${ }^{25}$ and the second in comproportionation of the corresponding $\mathrm{CuX}_{2}$ salt with copper powder or wire in refluxing acetonitrile (Scheme 1B). ${ }^{26}$

St. Petersburg State University, 7/9 Universitetskaya emb., 199034 St. Petersburg, Russia.E-mail: sergey.tunik@spbu.ru

$\dagger$ Electronic supplementary information (ESI) available: XRD patterns, NMR and IR spectra. See DOI: 10.1039/c8ra10564b
These approaches suffer of significant drawbacks such as using of toxic solvent - acetonitrile (A and B) and application of corrosive toxic acids (A) that is not desirable from the safety point of view. Additionally, availability of the corresponding $\mathrm{CuX}_{2}$ salts or $\mathrm{HX}$ acids are required for the synthesis of the complexes with desired counterions. Herein we report on the improved procedure for the synthesis of $\left[\mathrm{Cu}\left(\mathrm{CH}_{3} \mathrm{CN}\right)_{4}\right] \mathrm{X}\left(\mathrm{X}=\mathrm{BF}_{4}{ }^{-}, \mathrm{PF}_{6}{ }^{-}, \mathrm{ClO}_{4}{ }^{-}\right)$making it cheaper, safer and "greener".

\section{Results and discussion}

In our tactic we combined the methodology of Scheme 1B and basic principles of ion metathesis to develop simple, fast and effective one-pot comproportionation/metathesis method for the synthesis of $\left[\mathrm{Cu}\left(\mathrm{CH}_{3} \mathrm{CN}\right)_{4}\right] \mathrm{X}$ complexes (Scheme 2). As starting materials, we chose the copper(II) sulfate pentahydrate and the corresponding MX metal salts with desired counterions (MX: $\left.\mathrm{NaBF}_{4}, \mathrm{KPF}_{6}, \mathrm{LiClO}_{4}\right)$ since they are inexpensive, stable and low toxic. As a source of copper(0) we use copper wire instead of powder as it could be easily removed from the reaction mixture that makes product separation technology particularly convenient. All the compounds used in this reaction and the byproduct $\left(\mathrm{M}_{2} \mathrm{SO}_{4}\right.$ salt $)$ are watersoluble that makes possible to carry out the process in water using only a small excess of acetonitrile. At the same time the final products are low-soluble in water that allows isolation of the products as pure solids from the reaction

$$
\begin{aligned}
& \text { A. } \mathrm{Cu}_{2} \mathrm{O}+2 \mathrm{HX} \frac{\mathrm{NCMe}}{\text { reflux, } 30 \mathrm{~min}} 2[\mathrm{Cu}(\mathrm{NCMe}) 4] \mathrm{X}+\mathrm{H}_{2} \mathrm{O} \\
& \mathrm{X}=\mathrm{BF}_{4,}^{-} \mathrm{PF}_{6,}^{-} \mathrm{ClO}_{4}^{-} \\
& \text {B. } \mathrm{CuX} 2+\mathrm{Cu} \frac{\mathrm{NCMe}}{\text { reflux, } 30 \text { min }}[\mathrm{Cu}(\mathrm{NCMe}) 4] \mathrm{X}
\end{aligned}
$$

Scheme 1 Syntheses of $\left[\mathrm{Cu}\left(\mathrm{CH}_{3} \mathrm{CN}\right)_{4}\right] \mathrm{X}$ described in literature. 
$\left.\begin{array}{c}\mathrm{CuSO}_{4} \cdot 5 \mathrm{H}_{2} \mathrm{O}+\mathrm{Cu} \\ + \\ 2.7 \mathrm{MX}+8.2 \mathrm{NCMe}\end{array}\right] \frac{\mathrm{H}_{2} \mathrm{O}}{100^{\circ} \mathrm{C}, 30 \mathrm{~min}} \begin{gathered}2[\mathrm{Cu}(\mathrm{NCMe}) 4] \mathrm{X}+\mathrm{M}_{2} \mathrm{SO}_{4} \\ \mathrm{X}=\mathrm{BF}_{4}^{-}, \mathrm{PF}_{6,}^{-} \mathrm{ClO}_{4}^{-} 82-87 \%\end{gathered}$

Scheme 2 Suggested reaction scheme.

mixture by simple centrifugation with a considerable yields $(82-87 \%)$.

By varying the molar ratio of reagents, time and temperature we found optimal conditions for obtaining highly pure $\left[\mathrm{Cu}\left(\mathrm{CH}_{3} \mathrm{CN}\right)_{4}\right] \mathrm{X}\left(\mathrm{X}=\mathrm{BF}_{4}^{-}, \mathrm{PF}_{6}^{-}, \mathrm{ClO}_{4}^{-}\right)$complexes in high yields $(>80 \%)$. The protocol in brief can be described in the following way (see Experimental for details): copper(II) sulfate pentahydrate, alkali metal salt with bulky anion (2.7 eq.) were placed in a plastic vial followed by addition of water and acetonitrile (8.2 eq.); the salt and MeCN were added in a slight excess. The vial was then charged with copper wire and closed with cap. The reaction mixture was kept at $100{ }^{\circ} \mathrm{C}$ in water bath for $c a .30$ minutes, showing gradual disappearance of blue color of the starting solution (Fig. 1). The mixture obtained was then cooled to room temperature to give precipitate of white crystalline product, the copper wire was removed from the system and suspension was additionally cooled in fridge to complete crystallization of the product. The precipitate was then centrifuged, decanted, successively washed with water containing $c a$. $2 \%$ of $\mathrm{CH}_{3} \mathrm{CN}$ (slight amounts of acetonitrile were added at this and the next steps in order to prevent complex degradation), with ethyl acetate-ethanol mixture $1: 1$ containing $c a$. $4 \%$ of $\mathrm{CH}_{3} \mathrm{CN}$, with ethyl acetate containing $c a .2 \%$ of $\mathrm{CH}_{3} \mathrm{CN}$ and dried.

The presence of copper metal, $\mathrm{Cu}(0)$, in the reaction mixture prevents disproportionation of the product and/or its oxidation, which are typical detrimental channels of the copper(I) ions degradation in the presence of water. This approach is not new and was previously used by other researchers. ${ }^{27}$ The reaction products are poorly soluble in water that also shifts the reaction equilibrium toward the desired $\mathrm{Cu}(\mathrm{I})$ complex. Nevertheless, solubility varies for different counterions, we suppose it is slightly higher for the perchlorate complex compared to the tertafluoroborate and hexafluorophosphate compounds that result in lower yield of the reaction in the former case.

The products obtained were fully characterized by elemental analysis, X-ray powder diffraction analysis, ${ }^{1} \mathrm{H},{ }^{19} \mathrm{~F}$ NMR and IR spectroscopy, UV-VIS spectroscopy. All these

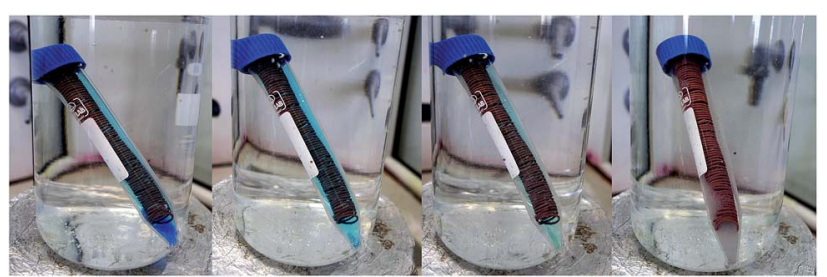

Fig. 1 Photographs showing the reaction mixture color changes during reaction. analyses confirm formation of high purity targeted compounds. XRD powder diffraction patterns for the complexes with $\mathrm{BF}_{4}{ }^{-}$and $\mathrm{ClO}_{4}{ }^{-}$counterions are in good agreement with those simulated from the data obtained for single crystal XRD (Fig. 2, $\mathrm{S} 1$ and $\mathrm{S} 2 \uparrow$ ). In the case of $\mathrm{PF}_{6}{ }^{-}$ there is some inconsistency that may be ascribed to the presence of acetonitrile molecules in all the structures uploaded to the CCDC, which we used for simulation. Additionally, we synthesized the corresponding complexes with $\mathrm{BF}_{4}{ }^{-}$and $\mathrm{PF}_{6}{ }^{-}$counterions using "classic" ${ }^{25}$ methodology and compared their powder diffraction patterns with those for complexes synthesized under the framework of the current study (Fig. S1 and S2 $\dagger$ ).

The IR spectra recorded in Nujol display the bands characteristic of the coordinated $\mathrm{C} \equiv \mathrm{N}$ bond ${ }^{1}$ together with the bands assigned to vibration frequencies of the corresponding counterion (Fig. 3). ${ }^{1,28}$

To make sure the completion of metathesis of the counterions we examine the ${ }^{1} \mathrm{H}$ and ${ }^{19} \mathrm{~F}$ NMR $\left(\mathrm{CDCl}_{3}\right)$ spectra of the complexes obtained with addition of 2 equivalents of 4 iodobenzotrifluoride (as an internal standard), in all the cases integral intensities of the signals of counterions and $p$ I- $\mathrm{C}_{6} \mathrm{H}_{4}-\mathrm{CF}_{3}$ are in good agreement with relative amount of fluorine in these compounds (Fig. 4, S3-S5 $\dagger$ ). The " $\mathrm{BaSO}_{4}$ test" for the $\mathrm{SO}_{4}{ }^{2-}$ anion detection also gave negative result that confirms completion of the metathesis. In the ${ }^{1} \mathrm{H}$ NMR spectra one sharp singlet signal at $c a .2 .22 \mathrm{ppm}$ occur with integral intensity corresponding to four acetonitrile molecules coordinated to copper(I) ion (Fig. 4, S3 and S4 †).

The completion of copper(II) reduction in the course of reaction was monitored by visible color change of reaction solution from blue to colorless. To make sure that final products have no admixture of corresponding copper(II) compounds we measured UV-VIS absorbance spectra of all

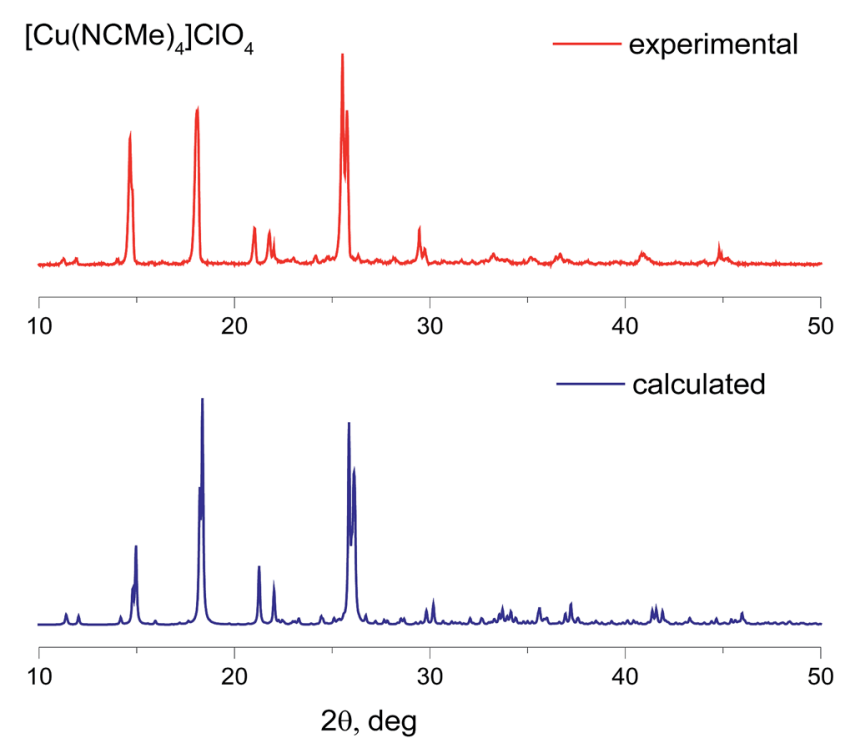

Fig. 2 Powder X-ray diffraction patterns of $\left[\mathrm{Cu}\left(\mathrm{CH}_{3} \mathrm{CN}\right)_{4}\right]\left[\mathrm{ClO}_{4}\right]$ : experimental (red) and calculated from the single-crystal data CCDC 772755 (blue). 


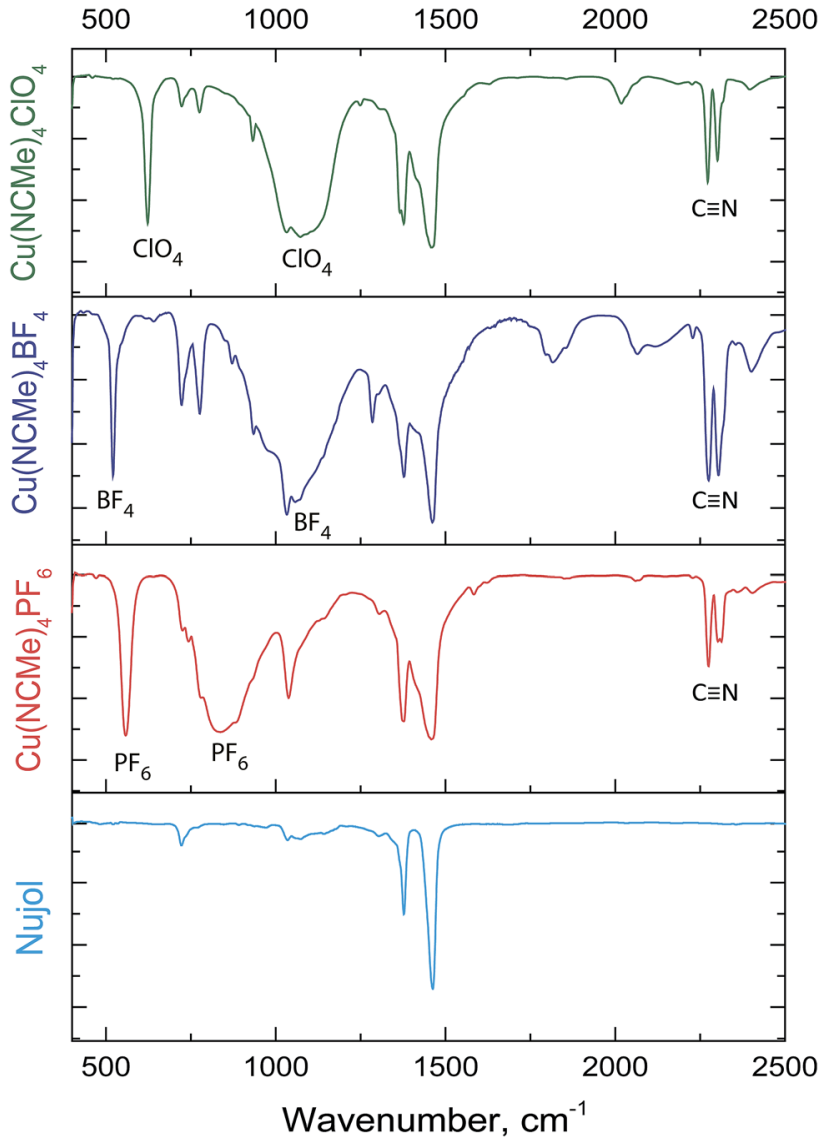

Fig. 3 IR spectra of $\left[\mathrm{Cu}(\mathrm{NCMe})_{4}\right] \mathrm{X}$ complexes in Nujol.

the complexes obtained in acetonitrile. The $\mathrm{Cu}\left(\mathrm{ClO}_{4}\right)_{2} \cdot 6 \mathrm{H}_{2} \mathrm{O}$ salt was used as a reference since it forms $\left[\mathrm{Cu}(\mathrm{MeCN})_{4}\right]$ $\left[\mathrm{ClO}_{4}\right]_{2}$ complex upon dissolving in acetonitrile. ${ }^{29}$ For all the compounds $0.01 \mathrm{M}$ solutions in acetonitrile were prepared and their UV-VIS absorbance spectra were measured in the range $250-1100 \mathrm{~nm}$ (Fig. 5).

The $\mathrm{Cu}(\mathrm{II})$ has clearly detectable strong absorption band in the $600 \geq 1100 \mathrm{~nm}$ interval. On the contrary, we did not find any

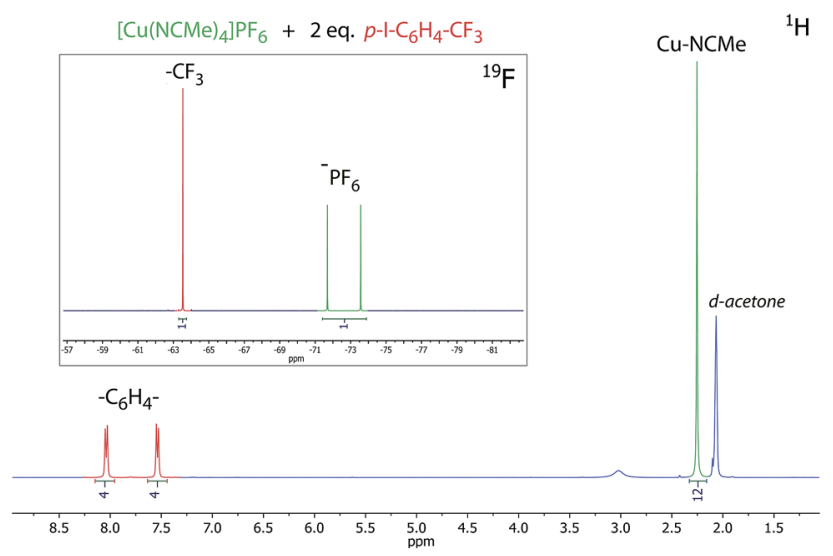

Fig. $4{ }^{1} \mathrm{H}$ and ${ }^{19} \mathrm{~F}$ (inset) NMR spectrum of $\left[\mathrm{Cu}\left(\mathrm{CH}_{3} \mathrm{CN}\right)_{4}\right]\left[\mathrm{PF}_{6}\right]$ in presence of 2 equivalents of 4 -iodobenzotrifluoride, acetone- $d_{6}, 298$ K.

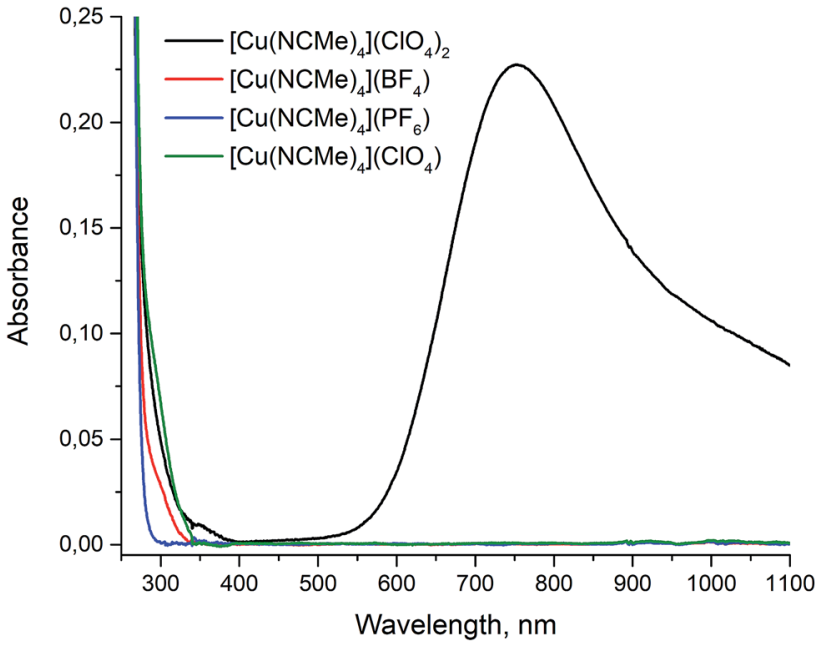

Fig. 5 UV-VIS spectra of $0.01 \mathrm{M}$ solutions of compounds in acetonitrile.

absorption for the samples obtained in the same spectral range, that clearly point to the absence of detectable amount of $\mathrm{Cu}(\mathrm{II})$ ions in the final products.

\section{Experimental}

\section{General comments}

$\mathrm{CuSO}_{4} \cdot 5 \mathrm{H}_{2} \mathrm{O}, \mathrm{Cu}\left(\mathrm{ClO}_{4}\right)_{2} \cdot 6 \mathrm{H}_{2} \mathrm{O}, \mathrm{NaBF}_{4}, \mathrm{KPF}_{6}, \mathrm{LiClO}_{4}$ and all the solvents were used as received. The solution $1 \mathrm{D}^{1} \mathrm{H},{ }^{19} \mathrm{~F}$ NMR spectra were recorded on a Bruker Avance 400 spectrometer. Microanalyses were carried out in the analytical laboratory of the University of Eastern Finland. The IR spectra were recorded in Nujol using a Fourier transform infrared spectrophotometer IRAffinity-1. X-ray powder diffraction analysis was carried out using a Rigaku Miniflex II ( $\mathrm{Cu} \mathrm{K} \alpha)$ diffractometer, equipped with a high-speed solid state Dtex type detector within the $2 \theta$ angle range of $5-100^{\circ}$ in the Bragg-Brentano geometry. The measurements were done with a scan step $0.02^{\circ}$ of $2 \theta$ and speed of $2^{\circ} \mathrm{min}^{-1}$. UV/VIS spectra were recorded using a Shimadzu UV-1800 spectrophotometer.

\section{General synthetic procedure exemplified by tetrakis(acetonitrile)copper(I) tetrafluoroborate}

$\left[\mathbf{C u}\left(\mathbf{C H}_{3} \mathbf{C N}\right)_{4}\right]\left[\mathbf{B F}_{4}\right]$. Copper(II) sulphate pentahydrate $(2.00 \mathrm{~g}$, $8.0 \mathrm{mmol}$, copper(II) nitrate can be used instead), sodium tetrafluoroborate $(2.38 \mathrm{~g}, 21.6 \mathrm{mmol}$, other alkali metal tetrafluoroborate can be used instead), acetonitrile (2.68 g, 65.4 mmol), copper wire coil $(d=0.7 \mathrm{~mm}, 60$ turns with $d=6 \mathrm{~mm}$, other metal copper source can be used instead) and distilled water $(c a .9 \mathrm{ml})$ were placed in a $16 \mathrm{ml}$ plastic vial and tightly closed with a cap. This mixture was shaken several times and put in boiling water bath for 10 minutes. Then the vial was taken out the bath and cooled to room temperature (RT) with water flow, shaken several times and put back into water bath for 10 minutes more. The operation (cooling - shaking - heating for 10 minutes) was repeated once or twice until blue color of 
$\mathrm{Cu}^{2+}$ disappeared. The resulting reaction mixture was cooled to RT, the copper wire was removed and the vial was again closed with the cap. The obtained white suspension in water was cooled in fridge to complete the precipitation of the product. It was then centrifuged, white solid was consistently washed and centrifuged twice with $5 \mathrm{ml}$ of water (containing $0.1 \mathrm{~g}$ of acetonitrile), two times with $5 \mathrm{ml}$ of ethyl acetate/ethanol 1:1 mixture (containing $0.2 \mathrm{~g}$ of acetonitrile) and twice with $5 \mathrm{ml}$ of ethyl acetate (containing $0.1 \mathrm{~g}$ of acetonitrile). The obtained precipitate was dried at $50{ }^{\circ} \mathrm{C}$ in air for 2 hours and then in vacuum at $\mathrm{RT}$ to give $4.34 \mathrm{~g}$ of the product as white crystalline solid (yield 86\%). ${ }^{19} \mathrm{~F}$ NMR (acetone-d ${ }_{6}, 298 \mathrm{~K} ; \delta$ ): -151.35 (s, $\mathrm{BF}_{4}$ ). ${ }^{1} \mathrm{H}$ NMR (acetone- $\mathrm{d}_{6}, 298 \mathrm{~K} ; \delta$ ): 2.22 (s, Cu-N $\equiv \mathrm{C}-\mathrm{Me}$ ), Anal. calcd for $\mathrm{C}_{8} \mathrm{H}_{12} \mathrm{BCuF}_{4} \mathrm{~N}_{4}$ : C, 30.16; H, 3.85; N, 17.81 found: C, 30.62; H, 3.83; N, 17.78. IR (in Nujol, v) 2275 (m), 2304 (m) $(\mathrm{C} \equiv \mathrm{N}) ; 1050(\mathrm{vs}), 521(\mathrm{~s})\left(\mathrm{BF}_{4}\right) \mathrm{cm}^{-1}$.

$\left[\mathbf{C u}\left(\mathbf{C H}_{3} \mathbf{C N}\right)_{4}\right]\left[\mathbf{P F}_{6}\right]$. Copper(II) sulphate pentahydrate $(1.00 \mathrm{~g}, 4.0 \mathrm{mmol})$, potassium hexafluorophosphate $(1.99 \mathrm{~g}$, $10.8 \mathrm{mmol}$, other alkali metal hexafluorophosphate can be used instead), acetonitrile (1.35 g, $32.9 \mathrm{mmol})$, distilled water (ca. $11 \mathrm{ml}$ ) were used as starting reagents. The product has been obtained as white crystalline solid, $2.60 \mathrm{~g}$ (yield $87 \%) .{ }^{19} \mathrm{~F}$ NMR (acetone- $\left.\mathrm{d}_{6}, 298 \mathrm{~K} ; \delta\right):-72.63\left(\mathrm{~d}, J_{\mathrm{P}-\mathrm{F}}=\right.$ $707.4 \mathrm{~Hz}, \mathrm{PF}_{6}$ ). ${ }^{1} \mathrm{H}$ NMR (acetone-d $\left.{ }_{6}, 298 \mathrm{~K} ; \delta\right): 2.22(\mathrm{~s}, \mathrm{Cu}-$ $\mathrm{N} \equiv \mathrm{C}-\mathrm{Me}$ ), Anal. calcd for $\mathrm{C}_{8} \mathrm{H}_{12} \mathrm{CuF}_{6} \mathrm{~N}_{4} \mathrm{P}$ : C, 25.78; $\mathrm{H}$, 3.25; N, 15.03 Found: C, 25.61; H, 3.24; N, 15.14. IR (in Nujol, v) $2275(\mathrm{~m}), 2311(\mathrm{~m})(\mathrm{C} \equiv \mathrm{N}) ; 850(\mathrm{vs}), 557(\mathrm{~s})\left(\mathrm{PF}_{6}\right) \mathrm{cm}^{-1}$.

$\left[\mathbf{C u}\left(\mathrm{CH}_{3} \mathbf{C N}\right)_{4}\right]\left[\mathrm{ClO}_{4}\right]$. Copper(II) sulphate pentahydrate $(2.00 \mathrm{~g}, 8.0 \mathrm{mmol})$, lithium perchlorate $(2.30 \mathrm{~g}, 21.6 \mathrm{mmol}$, other alkali metal perchlorate can be used instead), acetonitrile $(2.68 \mathrm{~g}, 65.4 \mathrm{mmol})$, distilled water ( $\mathrm{ca} .9 \mathrm{ml})$ were used as starting reagents. The product has been obtained as white crystalline solid, $4.29 \mathrm{~g}$ of (yield $82 \%$ ). ${ }^{1} \mathrm{H}$ NMR (acetone- $\mathrm{d}_{6}$, $298 \mathrm{~K} ; \delta): 2.22(\mathrm{~s}, \mathrm{Cu}-\mathrm{N} \equiv \mathrm{C}-\mathrm{Me})$, Anal. calcd for $\mathrm{C}_{8} \mathrm{H}_{12}{ }^{-}$ $\mathrm{ClCuN}_{4} \mathrm{O}_{4}$ : C, 29.37; H, 3.70; N, 17.12 found: C, 29.44; H, 3.75; N, 17.07. IR (in Nujol, v) 2272 (m), 2301 (m) (C三N); 1083 (vs), $623(\mathrm{~s})\left(\mathrm{ClO}_{4}\right) \mathrm{cm}^{-1}$.

\section{Conclusions}

In conclusion, we elaborated an efficient protocol for the synthesis of $\left[\mathrm{Cu}\left(\mathrm{CH}_{3} \mathrm{CN}\right)_{4}\right] \mathrm{X}$ complexes $\left(\mathrm{X}=\mathrm{BF}_{4}{ }^{-}, \mathrm{PF}_{6}{ }^{-}, \mathrm{ClO}_{4}{ }^{-}\right)$ using stable, inexpensive and low toxic materials. The protocol makes possible to carry out the reaction in aqueous media and minimizes the amount of toxic acetonitrile in the synthesis. According to this protocol the targeted complexes could be obtained in high yield (82-87\%) as pure crystalline material.

\section{Conflicts of interest}

There are no conflicts to declare.

\section{Acknowledgements}

This research has been supported by grant of the Russian Foundation for Basic Research 16-33-60109. The work was carried out using equipment of the Research park of St.
Petersburg State University (Centres for Magnetic Resonance, for Chemical Analysis and Materials Research, and for X-ray Diffraction Studies).

\section{Notes and references}

1 E. J. Parish, H. Qin, B. H. Lipshutz and C. Lee, Encycl. Reagents Org. Synth., 2007, DOI: 10.1002/9780470842898.rt039.pub2.

2 F. Wang, P. Chen and G. Liu, Encycl. Reagents Org. Synth., 2017, DOI: 10.1002/047084289X.rn02002.

3 B. Feng, L.-Q. Lu, J.-R. Chen, G. Feng, B.-Q. He, B. Lu and W.-J. Xiao, Angew. Chem., Int. Ed., 2018, 57, 5888-5892.

4 J. García-Álvarez, J. Díez and J. Gimeno, Green Chem., 2010, 12, 2127-2130.

5 S. M. Soria-Castro, D. M. Andrada, D. A. Caminos, J. E. Arguello, M. Robert and A. B. Penenory, J. Org. Chem., 2017, 82, 11464-11473.

6 X.-H. Ouyang, C. Hu, R.-J. Song and J.-H. Li, Org. Lett., 2018, 20, 4659-4662.

7 S. Seo and M. C. Willis, Org. Lett., 2017, 19, 4556-4559.

8 J. M. Hoover, J. E. Steves and S. S. Stahl, Nat. Protoc., 2012, 7, 1161.

9 X.-Y. Yu, Q.-Q. Zhao, J. Chen, J.-R. Chen and W.-J. Xiao, Angew. Chem., Int. Ed., 2018, 57, 15505-15509.

10 H.-J. Zhang and L. Yin, J. Am. Chem. Soc., 2018, 140, 1227012279.

11 T. C. Malig, D. Yu and J. E. Hein, J. Am. Chem. Soc., 2018, 140, 9167-9173.

12 P. K. Chikkade, Y. Kuninobu and M. Kanai, Chem. Sci., 2015, 6, 3195-3200.

13 L. Maestre, E. Ozkal, C. Ayats, Á. Beltrán, M. M. DíazRequejo, P. J. Pérez and M. A. Pericàs, Chem. Sci., 2015, 6, 1510-1515.

14 N. Armaroli, G. Accorsi, F. Cardinali and A. Listorti, Top. Curr. Chem., 2007, 280, 69-115.

15 M. Mohankumar, M. Holler, E. Meichsner, J.-F. Nierengarten, F. Niess, J.-P. Sauvage, B. DelavauxNicot, E. Leoni, F. Monti, J. M. Malicka, M. Cocchi, E. Bandini and N. Armaroli, J. Am. Chem. Soc., 2018, 140, 2336-2347.

16 A. F. Chaudhry, S. Mandal, K. I. Hardcastle and C. J. Fahrni, Chem. Sci., 2011, 2, 1016-1024.

17 M. Trose, F. Nahra and C. S. J. Cazin, Coord. Chem. Rev., 2018, 355, 380-403.

18 I. O. Koshevoy, A. J. Karttunen, J. R. Shakirova, A. S. Melnikov, M. Haukka, S. P. Tunik and T. A. Pakkanen, Angew. Chem., Int. Ed. Engl., 2010, 49, 8864-8866.

19 J. R. Shakirova, E. V Grachova, V. V Gurzhiy, S. K. Thangaraj, J. Jänis, A. S. Melnikov, A. J. Karttunen, S. P. Tunik and I. O. Koshevoy, Angew. Chem., Int. Ed., 2018, 57, 1415414158.

20 M. J. Leitl, D. M. Zink, A. Schinabeck, T. Baumann, D. Volz and H. Yersin, Top. Curr. Chem., 2016, 374, 25.

21 E. Fresta and R. D. Costa, J. Mater. Chem. C, 2017, 5, 56435675. 
22 C. E. Housecroft and E. C. Constable, Chem. Soc. Rev., 2015, 44, 8386-8398.

23 X.-L. Chen, C.-S. Lin, X.-Y. Wu, R. Yu, T. Teng, Q.-K. Zhang, Q. Zhang, W.-B. Yang and C.-Z. Lu, J. Mater. Chem. C, 2015, 3, 1187-1195.

24 H. H. Morgan, J. Chem. Soc., Trans., 1923, 123, 2901-2907. 25 G. J. Kubas, Inorg. Synth., 1979, 19, 90-92.

26 H.-C. Liang, K. D. Karlin, R. Dyson, S. Kaderli, B. Jung and A. D. Zuberbühler, Inorg. Chem., 2000, 39, 5884-5894.
27 J. S. Ovens, P. R. Christensen and D. B. Leznoff, Chem.-Eur. J., 2016, 22, 8234-8239.

28 N. E. Heimer, R. E. Del Sesto, Z. Meng, J. S. Wilkes and W. R. Carper, J. Mol. Liq., 2006, 124, 84-95.

29 A. S. Mereshchenko, P. K. Olshin, A. M. Karimov, M. Y. Skripkin, K. A. Burkov, Y. S. Tveryanovich and A. N. Tarnovsky, Chem. Phys. Lett., 2014, 615, 105-110. 